\title{
Inpatient management of alcohol withdrawal: a practical approach
}

SHIVEN B. CHABRIA ( $\square)$

Dept of Internal Medicine

Yale University School of Medicine Waterbury Hospital, Waterbury CT, USA

Phone: 203-573-6126

Fax: 203-573-6030

E-mail: shivenchabria@yahoo.com

SHIVEN B. CHABRIA

\begin{abstract}
Alcohol intake contributes directly or indirectly to 15 to $20 \%$ of medical problems in primary care or an inpatient setting. It is estimated that approximately 500,000 episodes of withdrawal will be severe enough to require pharmacologic intervention. The total cost to the United States economy from alcohol abuse was estimated to be $\$ 185$ billion for 1998. This review attempts to put forth a practical and evidence based approach towards the inpatient management of alcohol withdrawal. Various agents and their pharmacology are described. Strength of evidence regards to efficacy and shorter inpatient stays is examined.
\end{abstract}

Key words: substance abuse, pharmacology, addiction, pathophysiology, critical care

\section{Scope of the problem}

Two thirds of Americans drink alcohol and about ten percent of Americans abuse alcohol. Alcoholism is a very common problem and at some point every clinician will be confronted by it. Alcohol intake in its myriad forms contributes to the genesis of $15 \%$ to $20 \%$ of medical diagnoses in some way. Apart from the medical aspects of alcohol related problems it continues to be a costly drain on health care expenditure. In 1998 estimated healthcare costs to the United States economy from alcohol withdrawal alone approached a staggering one hundred and eighty five billion dollars. (1) In addition some costs of alcohol abuse are difficult to quantify, such as domestic violence, child abuse, or loss of a promising future. About half a million episodes of alcohol withdrawal per year are severe enough to require pharmacologic management. (2)

\section{Pathophysiology}

Alcohol is a central nervous system depressant. Abrupt cessation of alcohol intake unmasks the compensatory over activity of various parts of the central nervous system, most notably the sympathetic autonomic outflow. Data suggests that sustained alcohol intake with sustained blood alcohol levels correlated with incidence of alcohol withdrawal. Longer periods of sustained alcohol intake are more likely to produce withdrawal. (3) Neurotransmitters are thought to play an important role in the manifestations of alcohol withdrawal. The gamma amino butyric acid (GABA) receptor is down regulated and its neuronal activity decreased in alcohol withdrawal, resulting in hyper arousal. (4) Elevated levels of norepinephrine are found in the cerebrospinal fluid of patients in alcohol withdrawal. This is believed to be due to a decrease in the alpha-2 receptor-mediated inhibition of presynaptic norepinephrine release. (5) Dysfunctional serotonergic neurotransmission has been linked to an increased propensity toward ethanol addiction. (6)

\section{The alcohol withdrawal syndromes}

Clinical manifestations of alcohol with- drawal run the gamut from minor withdrawal symptoms to overt delirium tremens and withdrawal seizures. Table 1 elucidates the various syndromes and their respective timelines with a brief description of the clinical manifestations.

\section{Treatment of alcohol withdrawal}

Supportive measures: these play a critical role in the inpatient management of patients in withdrawal. Frequent re-evaluation of the patient is of paramount importance since the various withdrawal syndromes may coexist with or be mimicked by other conditions. Infection, trauma, metabolic derangements, drug overdose, hepatic failure, or gastrointestinal bleeding frequently complicate the clinical syndrome. When faced with altered sensorium without a definite cause it may be necessary to perform extensive testing, such as lumbar puncture and CT scan, to confidently exclude other diagnostic considerations, especially when patients present with fever in addition to a withdrawal syndrome.

Patients should be placed in a quiet, protective environment. Mechanical 
Table 1. Various alcohol withdrawal syndromes.

\begin{tabular}{|c|c|c|}
\hline Syndrome & Clinical manifestation & Onset after last drink \\
\hline $\begin{array}{l}\text { Minor withdrawal symptoms: } \\
\text { These usually resolve within } 24 \text { to } 48 \\
\text { hours }\end{array}$ & $\begin{array}{l}\text { Tremulousness, anxiety, headache, } \\
\text { diaphoresis, palpitations, Gl } \\
\text { symptoms including diarrhea and } \\
\text { anorexia }\end{array}$ & 6 to 36 hours \\
\hline $\begin{array}{l}\text { Alcohol related seizures, } \\
\text { Occur in approximately } 3 \% \text { of } \\
\text { chronic alcoholics }\end{array}$ & $\begin{array}{l}\text { Generalized, tonic-clonic, rarely } \\
\text { status epilepticus ( } 3 \% \text { of those with } \\
\text { seizures) }\end{array}$ & 6 to 48 hours \\
\hline $\begin{array}{l}\text { Alcoholic hallucinosis } \\
\text { Alcoholic hallucinosis refers to } \\
\text { hallucinations that develop within } \\
12 \text { to } 24 \text { hours of abstinence and } \\
\text { resolve within } 24 \text { to } 48 \text { hours (which } \\
\text { is the earliest point at which delirium } \\
\text { tremens typically develops) }\end{array}$ & $\begin{array}{l}\text { Hallucinations are usually visual, } \\
\text { although auditory and tactile } \\
\text { phenomena may also occur. } \\
\text { In contrast to delirium tremens, } \\
\text { alcoholic hallucinosis is not } \\
\text { associated with global clouding } \\
\text { of the sensorium, but with specific } \\
\text { hallucinations. }\end{array}$ & 12 to 48 hours \\
\hline $\begin{array}{l}\text { Delirium Tremens (DT), seen in } \\
\text { approximately } 5 \% \text { of those in } \\
\text { alcohol withdrawal. Has a mortality } \\
\text { rate of } 5 \% \text {. Death is usually due to } \\
\text { arrhythmias or complicating illnesses } \\
\text { such as pneumonia. }\end{array}$ & $\begin{array}{l}\text { DTs generally produce hallucinations, } \\
\text { disorientation, tachycardia, } \\
\text { hypertension, low-grade fever, } \\
\text { agitation, and diaphoresis. } \\
\text { Withdrawal may also have an } \\
\text { important impact on fluid and } \\
\text { electrolyte status. Almost all patients } \\
\text { in acute withdrawal are dehydrated } \\
\text { as a result of diaphoresis, } \\
\text { hyperthermia, vomiting, and } \\
\text { tachypnea. Hypokalemia is common } \\
\text { due to renal and extra-renal losses, } \\
\text { alterations in aldosterone levels, and } \\
\text { changes in potassium distribution } \\
\text { across the cell membrane. } \\
\text { Hypomagnesemia occurs frequently } \\
\text { with DTs and may predispose } \\
\text { to withdrawal seizures. (7) } \\
\text { Hypophosphatemia may occur due } \\
\text { to malnutrition, may be symptomatic, } \\
\text { and if severe, may contribute to } \\
\text { cardiac failure and rhabdomyolysis. }\end{array}$ & 48 to 96 hours \\
\hline
\end{tabular}

restraint with the patient in the lateral decubitus (or "swimmer's") position may be necessary for patients suffering from delirium tremens (DTs) for the protection of both the patient and his or her caretakers. Volume deficits can be calculated and replaced accordingly or, if there are no contraindications, isotonic intravenous fluid can be infused rapidly until patients are clinically euvolemic. Thiamine $100 \mathrm{mg}$ IV or $\mathrm{IM}$, should be administered prior to any glucose-containing solutions in order to decrease the risk of precipitating Wernicke's encephalopathy (WE) or Korsakoff's syndrome (KS). Multivitamins containing or supplemented with folate should be given routinely, and deficiencies of potassium, magnesium, glucose, and phosphate should be corrected as needed.

Intensive Care Unit referral: most intensive care patients tend to have severe alcohol withdrawal with electrolyte abnormalities that are life threatening, hence, indications for ICU referral is usually governed by clinical manifes- 
tations. Listed below are some of the useful criteria to determine intensive care unit referral. (8)

- Age greater than 40 with concomitant medical illness e.g. cardiac disease with failure, ischemia or angina, recent infarction

- Severe electrolyte imbalances especially with ECG changes, severe acid base disturbances

- Hemodynamic instability

- Respiratory insufficiency, hypoxemia and or hypercapnia

- Potentially serious infections, including sepsis

- Gl pathology including pancreatitis, Gl bleeding, fulminant hepatic failure, peritonitis

- Persistent hyperthermia (Tmax $>390$ or $103^{\circ} \mathrm{F}$ )

- Rhabdomyolysis

- Renal failure

- Prior history of severe Delirium Tremens

- Need for IV benzodiazepines or other IV drips to control withdrawal.

\section{Pharmacotherapy of alcohol withdrawal}

\section{Benzodiazepines}

These act on the gamma amino butyric acid (GABA) class of receptors. As a class effect they promote the binding of the major inhibitory neurotransmitter GABA to the GABA A sub type of the GABA receptors enhancing the frequency of GABA chloride channel openings

From a pharmacokinetic perspective most benzodiazepines have active metabolites and hence the duration of action seems to exceed the plasma half life.

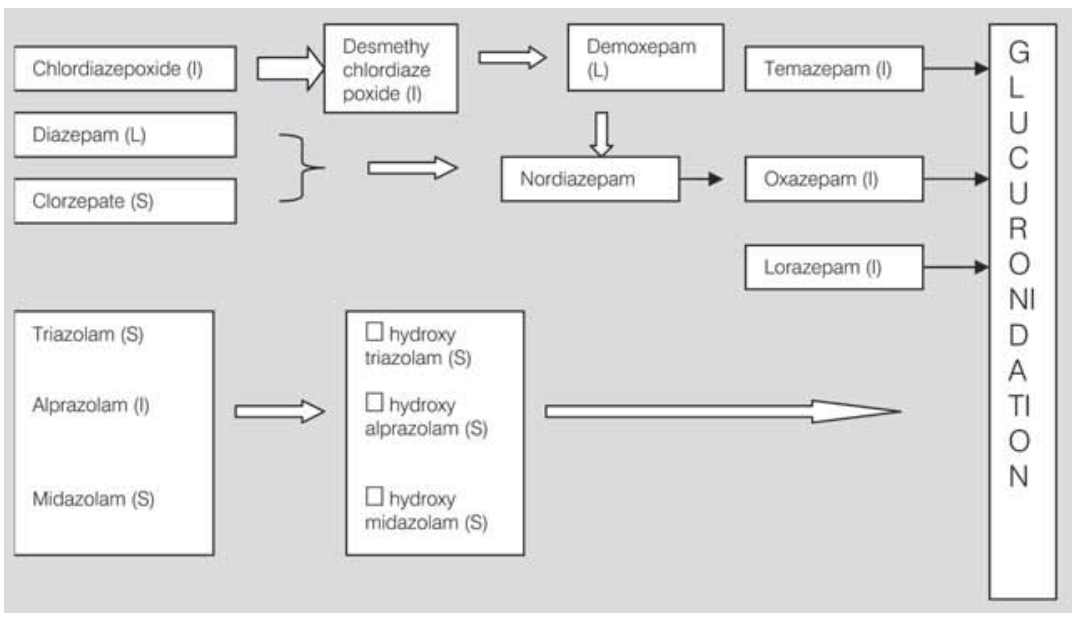

Figure 1. Metabolic degradation and plasma half lives of selected benzodiazepines.

Figure 1 below demonstrates the metabolic relationships between the various benzodiazepines. The approximate half life of the compounds is in parenthesis. $\mathrm{S}=$ short acting with half life $<6 \mathrm{hrs}$, I = intermediate with half lives $6-24$ hrs, and $L=$ long acting with half life $>24 \mathrm{hrs}$.

In general, the longer acting agents with active metabolites are preferred since they are associated with a smoother course and less chance of recurrent withdrawal. (9) Conversely, Lorazepam, Oxazepam or Temazepam might be used in patients with advanced liver disease since they do not have active metabolites and with shorter half lives are less likely to cause over sedation. The oral route is preferred if the patient can take medication orally. If the patient is too agitated or disoriented, IV route can be used. We do not advocate the use of IM administration since the absorption of the drug can be erratic and unpredictable. If IV access is temporarily unavailable, IM Lorazepam can be used. (10) Table 2 gives approximate dosage equivalence with plasma half lives.

\section{Dose titration}

As a general guideline, younger patients with paucity of co morbid factors can be kept lightly sedated. Older patients with several cardio pulmonary co morbid risks factors usually need more sedation and monitoring in the intensive care unit. The contention is that this sub group is at more risk and may not tolerate the systemic stress of major withdrawal.

The decision to put the patient on fixed drug therapy versus symptom triggered therapy should be made depending upon the severity of the withdrawal and prior history of delirium tremens and/or seizures. Symptom triggered therapy involves treatment only when the patient manifests symptoms. This is

Table 2. Approximate dose equivalence and half lives. (11)

\begin{tabular}{ccc}
\hline Drug name & $\begin{array}{c}\text { Approximate dose } \\
\text { equivalent in } \mathbf{~ m g}\end{array}$ & $\begin{array}{c}\text { Elimination half life } \\
\text { In hours }\end{array}$ \\
\hline Chlordiazepoxide & 25 & $5-30$ \\
\hline Diazepam & 5 & $20-80$ \\
\hline Lorazepam & $0.75-1$ & $10-20$ \\
\hline Oxazepam & 15 & $5-20$ \\
\hline
\end{tabular}


a reasonable strategy for the younger, less complicated patient. The use of symptom triggered therapy in selected patients was associated with similar outcomes when compared to fixed drug schedules. However, the symptom triggered group received less amounts of Benzodiazepines and the duration of treatment was shorter. (12) Our personal experiences and practices involve using the symptom triggered approach for the younger patient with fewer co morbid conditions in mild to moderate withdrawal. The fixed dosing schedule is used in severe alcohol withdrawal with additional allowance for symptom triggered medications added on to the regimen.

\section{Use of the CIWA -Ar scale}

The CIWA- Ar scale (The Clinical Institute Withdrawal Assessment for alcohol scale) is used widely as a means to gauge the severity of alcohol withdrawal. (13) Though this scale is useful, routine use of the scale alone is not sufficient to assess the severity of alcohol ?dependency/withdrawal. Most patients in acute alcohol withdrawal have multiple other co morbid conditions. CIWA-Ar alone fails to take into consideration delirium from potential etiologies other than alcohol withdrawal syndrome. (14) Thus, an exhaustive history, physical and diagnostic evaluation is a necessary adjunct to the use of the CIWA-Ar scale.

The CIWA -Ar is a numeric scale with numbers being assigned to severity of symptoms such as anxiety, nausea, headache and several other parameters. This brings in an element of subjectivity. For example a nurse might score 4 on a patient's tremor while another nurse might ascribe a score of 6 to the same tremor. This inter observer variability can be mitigated to an extent by both nurses obtaining the CIWA - Ar score together at shift changes in the hospital.

The practice of having pathways in institutions where a fixed dose of a benzodiazepine is attached to a number on the CIWA scale is fraught with inadequacies. A CIWA -Ar score in such a prac- tice might merit a dose of benzodiazepine without taking into account age, liver function, previous withdrawal and or seizures and body weight. Thus, the patient could get too little or too much depending on the clinical situation. The most practical and pragmatic approach involves using the CIWA -Ar as a guiding tool and then the individual physician should decide upon the agent, its dose, frequency and route based on clinical decision making.

\section{Severe refractory alcohol withdrawal}

Severe refractory alcohol withdrawal/ delirium tremens can be seen occasionally. Patients continue to withdraw despite treatment with very high doses of benzodiazepines. These patients might have low endogenous levels of GABA or conformational changes in the GABA receptor preventing effective signaling and thus diminished efficacy of benzodiazepines. (15) In such patients, barbiturates, more specifically phenobarbital, can be very effective when given in addition to benzodiazepines. The combined effect of benzodiazepines, which increase the frequency of GABA chloride channel opening, and barbiturates, which increase the duration of channel opening might enhance therapeutic responsiveness. Another reasonable alternative is propofol, which acts to open chloride channels in the absence of GABA, and may also antagonize the excitatory amino acids that are up regulated during alcohol withdrawal. $(16,17)$ The use of Phenobarbital and propofol usually needs an intensive care unit environment and very often mechanical ventilation.

\section{Other pharmacologic agents}

Ethanol: alcohol should not be used as a treatment in acute withdrawal. There are other agents and alternatives that appear to be safer and more efficacious. (18)

Baclofen: baclofen is a selective agonist of the GABA - B receptor. (19) It is thought to exert its anti-spastic effect through this mechanism. The use of baclofen in acute alcohol withdrawal has been studied. (20) It appears to be equally efficacious as benzodiazepines and no significant differences were found between the groups receiving benzodiazepines and baclofen. However, baclofen is known to lower the seizure threshold and more information is needed prior to its routine use in alcohol withdrawal.

Antipsychotics - Phenothiazines and butyrophenones lower the seizure threshold. They should be used with extreme caution in the withdrawing alcoholic. These agents may also interfere with heat dissipation and, perhaps most importantly, do not exhibit crosstolerance with alcohol thus their efficacy is suspect.

Antiepileptics: There is some interest in the use of anti-epileptics for the treatment of acute alcohol withdrawal. In initial studies carbamazepine, an anticonvulsant agent widely used in Europe for alcohol withdrawal syndrome, was shown to decrease the severity of withdrawal symptoms comparable to the benzodiazepines in terms of adverse events, and was equally as effective as lorazepam in decreasing the symptoms of alcohol withdrawal. (21-23) However, a subsequent systemic review of a heterogeneous group of trials was unable to draw definite conclusions based on the variable study designs employed and the low overall mortality rates observed. (24) Hence, there is not a large enough body of evidence to suggest using carbamazepine in acute alcohol withdrawal.

Chlormethiazole: It is a drug which is structurally related to thiamine (vitamin B1) but acts like a sedative, hypnotic, muscle relaxant and anticonvulsant. Chlormethiazole is a positive modulator of $y$-aminobutyric acid (GABA) ŠAĆ receptors. (25) Its use in the treatment of alcohol withdrawal is not well established. It is widely used in alcohol withdrawal in Europe. Certain European studies allude to its efficacy in the treatment of alcohol withdrawal. (2628) Intravenous infusions of this agent may cause cardiac arrhythmias and 
hepatotoxicity with this agent has been reported. (29) It does not appear to be superior to benzodiazepines in alcohol withdrawal and more data is needed to recommend its use.

Other agents with purported efficacy in alcohol withdrawal include gamma hydroxyl butyrate, (30) sodium valproate, $(31)$ gabapentin. $(32,33)$ However, the use of these agents remains off label. Large double blinded trials are required before recommending their routine use for alcohol withdrawal.

\section{Drug interactions from alcohol use}

The interaction of alcohol with the CYP-450 enzyme system can be complex and depends upon the duration of alcohol consumption. (34) Shortterm consumption leads to a competitive inhibition of the CYP2E1 enzyme, whereas chronic use leads to its induction. CYP2E1 induction leads to an increased clearance of drugs such as warfarin, diazepam, rifamycin, meprobamate, pentobarbital, propranolol, and alcohol itself, with the effect upon liver metabolism lasting for days to weeks after the discontinuation of alcohol. More importantly, the CYP2E1 enzyme system converts otherwise safe substances into highly toxic metabolites. These include industrial solvents, cocaine, some anesthetic agents (e.g., enflurane, methoxyflurane), isoniazid, phenylbutazone, and acetaminophen. Through the induction of this alternate pathway of drug metabolism, ordinarily innocuous doses of these agents may become hepatotoxic.

\section{Conclusions}

Alcohol withdrawal remains a leviathan cause of healthcare expenditure. A thorough history and physical examination should precede the diagnosis of alcohol withdrawal. Other causes of delirium should be ruled out and patient's co morbid medical illnesses must be treated. Benzodiazepine class drugs remain the agents of choice. Longer acting agents are preferred because many have active metabolites that prevent rapid loss of action. If possible oral medications should be tried. Symptom triggered approach is as effective as standing dose regimens.

Delirium tremens should be treated early and aggressively with close monitoring of electrolytes and vital signs. Often the intravenous route is used for administration of drugs since there is clouding of the sensorium. Refractory delirium tremens usually responds to barbiturates and propofol administered in an intensive care unit setting and may require mechanical ventilation. Severe delirium tremens usually requires massive doses of benzodiazepines. The CIWA-Ar scale is a useful tool to gauge the severity of withdrawal. However, the physician should take into account patient factors prior to prescribing benzodiazepines based on the CIWA score.

\section{REFERENCES}

1. Harwood HJ. Updating estimates of the economic costs of alcohol abuse in the United States: estimates, update methods and data. Report prepared by The Lewin Group for the National Institute on Alcohol Abuse and Alcoholism, 2000.

2. O'Connor PG, Schottenfeld RS. Patients with alcohol problems. N Engl J Med 1998;338:592-602.

3. Isbell $\mathrm{H}$, Fraser HF, Wikler A, Belleville RE, Eisenman AJ. An experimental study of the etiology of rum fits and delirium tremens. Q J Stud Alcohol 1955;16:1-33.

4. Turner RC, Lichstein PR, Peden JG Jr, Busher JT, Waivers LE. Alcohol withdrawal syndromes: A review of pathophysiology, clinical presentation, and treatment. J Gen Intern Med 1989;4:432-44.

5. Hawley RJ, Major LF, Schulman EA, Linnoila M. Cerebrospinal fluid 3-methoxy-4-hydroxyphenylglycol and norepinephrine levels in alcohol withdrawal. Correlations with clinical signs. Arch Gen Psychiatry 1985;42:1056-62.

6. Mantere T, Tupala E, Hall H, Särkioja T, Räsänen P, Bergström K, et al, editors. Serotonin transporter distribution and density in the cerebral cortex of alcoholic and nonalcoholic comparison subjects: a whole-hemisphere autoradiography study. Am J Psychiatry 2002;159:599-602.

7. Victor M. The role of hypomagnesemia and respiratory alkalosis in the genesis of alcohol-withdrawal symptoms. Ann N Y Acad Sci 1973;215:235-48.

8. Carlson RW, Keske B, Cortez A. Alcohol withdrawal syndrome: alleviating symptoms, preventing progression. J Crit lllness 1998;13(5):311-7.

9. Saitz R, O'Malley SS. Pharmacotherapies for alcohol abuse. Withdrawal and treatment. Med Clin North Am 1997;81:881-907.

10. Mayo-Smith MF, Beecher LH, Fischer TL, Gorelick DA, Guillaume JL, Hill A, et al, editors. Management of alcohol withdrawal delirium: an evidence-based practice guideline. Arch Intern Med 2004;164:1405-12.

11. Kirkwood CK, Melton ST. Anxiety disorders. In: DiPiro JT, Talbert RL, Yee GC, et al, editors. Pharmacotherapy: a Pathophysiologic Approach. 5th ed. 2002;71:1289-310.

12. Daeppen JB, Gache P, Landry U, Sekera E, Schweizer V, Gloor S, et al, editors. Symptom-triggered vs fixed-schedule doses of benzodiazepine for alcohol withdrawal: a randomized treatment trial. Arch Intern Med 2002;162:1117-21.

13. Sullivan JT, Sykora K, Schneiderman J, Naranjo CA, Sellers EM. Assessment of alcohol withdrawal: The revised Clinical Institute Withdrawal Assessment for Alcohol scale (CIWA-Ar). Br J Addict 1989;84:1353-7. 
14. Bostwick JM, Lapid MI. False positives on the clinical institute withdrawal assessment for alcohol-revised: is this scale appropriate for use in the medically ill? Psychosomatics 2004;45:256-61.

15. Cagetti E, Liang J, Spigelman I, Olsen RW. Withdrawal from chronic intermittent ethanol treatment changes subunit composition, reduces synaptic function, and decreases behavioral responses to positive allosteric modulators of GABAA receptors. Mol Pharmacol 2003;63:53-64.

16. McCowan C, Marik P. Refractory delirium tremens treated with propofol: A case series. Crit Care Med 2000;28:1781-4.

17. Coomes TR, Smith SW. Successful use of propofol in refractory delirium tremens. Ann Emerg Med 1997;30:825-8.

18. Mayo-Smith MF. Pharmacological management of alcohol withdrawal. A meta-analysis and evidence-based practice guideline. American Society of Addiction Medicine Working Group on Pharmacological Management of Alcohol Withdrawal. JAMA 1997; 278:144-51.

19. Colombo G, Serra S, Brunetti G, Vacca G, Carai MA, Gessa GL. Suppression by baclofen of alcohol deprivation effect in Sardinian alcoholpreferring (sP) rats. Drug Alcohol Depend 2003;70:105-8.

20. Addolorato G, Caputo F, Capristo E, Janiri L, Bernardi M, Agabio R, et al, editors. Rapid suppression of alcohol withdrawal syndrome by baclofen. Am J Med 2002;112:226-9.

21. Stuppaeck $\mathrm{CH}$, Pycha R, Miller C, Whitworth AB, Oberbauer H, Fleischhacker WW. Carbamazepine versus oxazepam in the treatment of alcohol withdrawal: a double-blind study. Alcohol 1992;27:153-8.

22. Malcolm R, Ballenger JC, Sturgis ET, Anton R. Double-blind controlled trial comparing carbamazepine to oxazepam treatment of alcohol withdrawal. Am J Psychiatry 1989;146:617-21.

23. Malcolm R, Myrick H, Roberts J, Wang W, Anton RF, Ballenger JC. The effects of carbamazepine and lorazepam on single versus multiple previous alcohol withdrawals in an outpatient randomized trial. J Gen Intern Med 2002;17:349-55.

24. Polycarpou A, Papanikolaou P, loannidis J, Contopoulos-loannidis D. Anticonvulsants for alcohol withdrawal. Cochrane Database Syst Rev 2005; (3):CD005064.

25. Gasior M, Witkin JM, Goldberg SR, Munzar P. Chlormethiazole potentiates the discriminative stimulus effects of methamphetamine in rats. Eur J Pharmacol 2004;494:183-9.

26. Morgan MY. The management of alcohol withdrawal using chlormethiazole. Alcohol 1995;30:771-4.

27. Schied HW, Kimmerle K, Braunschweiger M. A retrospective comparison of delirium tremens cases before and after the availability of chlormethiazole. Acta Psychiatr Scand Suppl 1986;329:157-61.

28. Shaw GK. Chlormethiazole in the management of alcohol withdrawal. Acta Psychiatr Scand Suppl 1986;329:162-6.

29. Heinemann F, Assion HJ. Hepatotoxic side-effect of clomethiazole. Pharmacopsychiatry $1996 ; 29: 196-7$.

30. Nimmerrichter AA, Walter H, Gutierrez-Lobos KE, Lesch OM. Double-blind controlled trial of gamma-hydroxybutyrate and clomethiazole in the treatment of alcohol withdrawal. Alcohol 2002;37:67-73.

31. Myrick H, Brady KT, Malcolm R. Divalproex in the treatment of alcohol withdrawal. Am J Drug Alcohol Abuse 2000;26:155-60.

32. Myrick H, Malcolm R, Brady KT. Gabapentin treatment of alcohol withdrawal. Am J Psychiatry 1998;155:1632.

33. Voris J, Smith NL, Rao SM, Thorne DL, Flowers QJ. Gabapentin for the treatment of ethanol withdrawal. Subst Abus 2003;24:129-32.

34. Lieber CS. Medical disorders of alcoholism. N Engl J Med 1995;333:1058-65. 